\title{
The dental status of cardiac patients
}

\author{
Allan R. Thom ${ }^{1}$ and Geoffrey L. Howe \\ From the Department of Oral Surgery, St. Thomas' Hospital, London
}

Fifty patients, all with severe heart disease, were questioned about their past medical and dental history, and examined, clinically and radiographically, to ascertain their dental status. Only I4 patients were considered to be dentally fit, 7 of whom were edentulous. Thirty-nine patients sought dental treatment for the relief of pain alone, and their dental condition was far from satisfactory. Less than one-quarter of the patients included in this study had been warned of the need for maintenance of a high degree of dental fitness and prophylactic measures before treatment. Forty-three had never had a medical history taken before dental treatment was performed. These findings indicate that there is room for improvement in the provision of dental care for cardiac patients, and recommendations are made as to how this might be achieved.

The importance of dental disease in the aetiology of subacute bacterial endocarditis has been repeatedly stressed in published reports. Though a bacteraemia from dental manipulation is usually transitory (Northrop and Crowley, 1943; Robinson et al., 1950a, b), it is still a potential threat to patients with congenital or rheumatic heart disease, and especially to those patients in whom a prosthetic valve has been inserted. The morbidity from subacute bacterial endocarditis is immense while the mortality according to Fleming (1970) may be between 30 and 40 per cent, increasing to 75 per cent when the patient has an artificial valve (Braimbridge, 1969).

As prevention is preferable to cure, some authors (Hobson and Juel-Jensen, 1956; Beeley, 1969; Hovell, 1970) have advocated that patients who have had one attack of subacute bacterial endocarditis should be rendered endentulous. The need for impeccable dental care has been stressed many times, and it has been stated that 'a second attack despite such care is an indication for dental clearance' (British Medical fournal, 1967). However, the mouth may not be the only source of the Streptococcus viridans causing endocarditis, and so other authorities feel that the extraction of healthy teeth is not indicated (Lancet, 197I).

Certainly the removal of the teeth is not without its dangers. Recent articles (Cameron,

Received 23 May 1972.

\footnotetext{
${ }^{1}$ Present address: Department of Orthodontics, Royal Dental Hospital, London.

2 Present address: Department of Oral Surgery, Royal Dental Hospital, London.
}

1971; Croxson, Altmann, and O'Brien, 197I ; Simon and Goodwin, 197I) have drawn attention to the fact that Streptococcus viridans endocarditis can occur in the edentulous patient, and may even be a consequence of oral ulceration caused by ill-fitting dentures.

Perhaps more attention should be paid to the prevention of oral sepsis in susceptible patients. The periodontal structures require special consideration, as disease affecting them is probably more important than dental caries and its sequelae in the aetiology of subacute bacterial endocarditis. Some authors have shown that the incidence of bacteraemia is increased when teeth are extracted in the presence of gum disease or when periodontal procedures are undertaken (Table I).

\section{Prevention, prophylaxis, and precautions}

It is not widely realized that considerable advances have been made in preventive dentistry in recent years. Fluoride, ingested in drinking water or applied topically, and fissure sealants appear to have a role to play in preventive dentistry for children with congenital heart disease.

Where attempts to prevent dental disease have failed it is obviously logical to take reasonable precautions to prevent the first attack of subacute bacterial endocarditis. Antibiotic cover should be given to 'patients at risk' before dental or oral procedures. However, there is lack of agreement concerning the criteria used to determine which patients are 
'at risk', and also with regard to the dental procedures for which antibiotic cover is indicated. In a recent paper, Jolly and Drucker (I97I) suggest that any manipulation or procedure that is likely to open blood vessels should be performed under antibiotic cover.

Penicillin remains the drug of choice, except in patients with a history of sensitivity to or recent prophylactic treatment with it. Attention has been drawn to the early emergence of resistant strains of streptococci following the administration of penicillin (British Medical fournal, 197I) and alternative regimens have been suggested (American Heart Association, 1965; Tozer, Boutflower, and Gillespie, 1966; Phillips and Warren, 1972).

The commonly recommended antibiotic regimen for patients with rheumatic heart disease may be inadequate for those in whom prosthetic valves have been inserted. In these cases once infection becomes established within the tissues related to the prosthesis it is almost always fatal. Three cases of bacterial endocarditis in such patients were reported by Cohn et al. (1966) and one death clearly resulted from dental extractions even though antibiotic cover had been given.

Recent work (Jones et al., 1970; Cutcher et $a l ., 1971$; Scopp and Orvieto, 197I) indicates that oral rinses and gingival sulcus irrigation with antiseptic solutions before extraction may decrease the incidence of bacteraemia as well as the number of organisms present in the sulci. These measures appear to be worthy of more widespread application in clinical practice, though they can in no respect be regarded as a substitute for antibiotic cover.

Measures to reduce the incidence of bacterial endocarditis, and more especially to prevent the need for extractions, must be taken by the patient, his physician, and the dentist, working as a team. The patient should be indoctrinated with the importance of preventive dentistry, the imperative need for regular dental care, and the necessity for precautions to be taken whenever dental treatment is performed. An adequate medical history must be obtained from every patient before dental treatment is given. Unfortunately some of the patients most at risk will disclose that they have a cardiac condition or history of rheumatic fever only on direct questioning.

We were dismayed to find little evidence of widespread understanding of these problems, or attempts at prophylaxis, during our everyday clinical practice in a general hospital, and so we decided to investigate the current situation by means of a prospective study.
TABLE I

\begin{tabular}{lll}
\hline Investigator & Procedure undertaken & Bacteraemia (\%) \\
\hline $\begin{array}{l}\text { Okell and Elliott } \\
\text { (1935) }\end{array}$ & $\begin{array}{l}\text { Multiple extractions in presence of obvious } \\
\text { gum disease } \\
\text { Multiple extractions in presence of moderate }\end{array}$ & 75 \\
$\begin{array}{l}\text { gum disease } \\
\text { Extraction with no detectable gum disease }\end{array}$ & 34 \\
Elliott (1939) & $\begin{array}{l}\text { Rocking one tooth affected by obvious gum } \\
\text { disease }\end{array}$ & 86 \\
& $\begin{array}{l}\text { Rocking one tooth with no detectable gum } \\
\text { disease }\end{array}$ & 25 \\
Rogosa et al. & $\begin{array}{l}\text { Extraction of teeth } \\
\text { Periodontal procedures }\end{array}$ & 82 \\
\hline
\end{tabular}

\section{Design of study}

The past dental history and oral condition of 50 consecutive patients, all with a serious heart condition, were investigated. They had been referred to one centre from many sources for possible cardiac surgery. Forty-six had mitral or aortic valve disease while the other 4 had congenital heart disease with a ventricular septal defect.

A dental history and careful examination of teeth and gums, which included full mouth intraoral periapical radiographs, were undertaken for each of these patients when they were admitted for cardiac catheterization and investigation by the Department of Cardio-Thoracic Surgery.

\section{Results}

Age and sex Sex distribution was equal, and the ages ranged from 23 to 62 years. Sixty per cent of patients were aged between 45 and 59 years.

Past medical history Twenty-nine patients gave a history of having had rheumatic fever, and Io of these had had more than one attack. Subacute bacterial endocarditis had been diagnosed and treated in 7 patients.

The length of time that had elapsed since they had been informed of their cardiac condition by a doctor varied from a few months to 50 years, the mean for the whole group being 18 years.

Thirty-six patients, 72 per cent of the series, attended a cardiac review clinic regularly and were under constant supervision by their general medical practitioner or cardiologist. The remainder sought advice only when they had symptoms which troubled them.

Past dental history An accurate history relating to past dental procedures was difficult to elicit from the majority of patients. However, 3I could definitely remember having had extractions without antibiotic cover since their heart condition was diagnosed. Twelve patients had received antibiotic cover or 
'special injections' before extractions, 5 of whom had the procedure carried out in a hospital.

The patients were divided into two groups, those who attended a dentist regularly, and those who did not.

Group A: Patients who visited a dentist regularly Only I I patients, 22 per cent of the series, had undergone a dental examination once or more a year, and 7 of these could be regarded as dentally fit on clinical and radiographic examination. Three had some evidence of periodontal disease, and one a retained root showing no signs of infection (Helsham, 1960). There was no evidence of either tooth decay or other lesions in this group.

Group B: Patients who visited a dentist irregularly Thirty-nine patients, 78 per cent of the series, sought dental care on an irregular basis and usually only for the relief of pain. Seven of these, 6 of whom were edentulous, were considered to be dentally fit. The seventh patient had only 6 standing teeth, the rest having been extracted and replaced by dentures. The incidence of oral and dental sepsis was far higher than in Group A (Table 2). Three typical conditions are illustrated in Fig. I-4.

'Edentulous' patients Full dentures were worn by I I patients, 7 of whom were dentally fit. Of the remaining 4, one had a retained root, another an impacted wisdom tooth, while the other 2 were afflicted with candidiasis, and one of these also had an ulcerating denture granuloma.

\section{Preventive measures}

By a doctor No patient in the series had ever been referred for preventive dentistry or had arrangements made for regular dental inspection. Twelve patients $(24 \%)$ had been told by a doctor of the need for prophylactic measures before dental treatment. One of these patients knew that antibiotic cover was necessary when extractions were undertaken and the remainder understood that the dentist should use a 'special injection'. Half of the dentally fit patients included in this study had been warned.

By a dentist None of these patients had been given advice concerning preventive dentistry or offered treatment other than dental care of a routine nature. A large majority of them, 43 patients, had never been
TABLE 2 Findings on clinical and radiographic examination of 50 patients

\begin{tabular}{|c|c|c|}
\hline & \multicolumn{2}{|c|}{ Frequency of dental examination } \\
\hline & \multirow{2}{*}{$\begin{array}{l}\text { Regularly } \\
\begin{array}{l}\text { Group } A \\
\text { (II cases) }\end{array}\end{array}$} & \multirow{2}{*}{$\begin{array}{l}\text { Rarely } \\
\text { Group } B \\
\text { (39 cases) }\end{array}$} \\
\hline & & \\
\hline Dentally fit & $7(63 \cdot 6 \%)$ & $7(17 \cdot 9 \%)$ \\
\hline Edentulous & I $(9 \cdot 1 \%)$ & II $(28 \cdot 2 \%)$ \\
\hline Retained roots (no clinical evidence of infection) & I $(9 \cdot 1 \%)$ & $9(23 \cdot 1 \%)$ \\
\hline Retained roots and teeth with apical infection & o & $7(17 \cdot 9 \%)$ \\
\hline Caries (clinical) & & I0 $(25 \cdot 6 \%)$ \\
\hline Periodontal disease (clinical and radiographic) & $3(27 \cdot 3 \%)$ & $20(5 \mathrm{I} \cdot 3 \%)$ \\
\hline Impacted wisdom teeth & o & $3(7 \cdot 7 \%)$ \\
\hline Candidiasis infection & 0 & $3(7 \cdot 7 \%)$ \\
\hline
\end{tabular}

NB The fact that some patients had more than one lesion makes it impossible to total the numbers.

questioned by a dentist about their past medical history. Of the 7 who had been, 3 were dentally fit and received regular dental treatment.

Dental extractions without antibiotic cover had been performed on 3 patients within the preceding few months. One of these cases had a history of at least two previous attacks of subacute bacterial endocarditis. She was warned by her medical practitioner regarding precautions before dental treatment. She chose to ignore his advice; no medical history was taken by her dentist and multiple extractions were carried out without antibiotic cover.

FI G. I The dental condition of a 34-year-old patient afflicted with congenital heart disease.

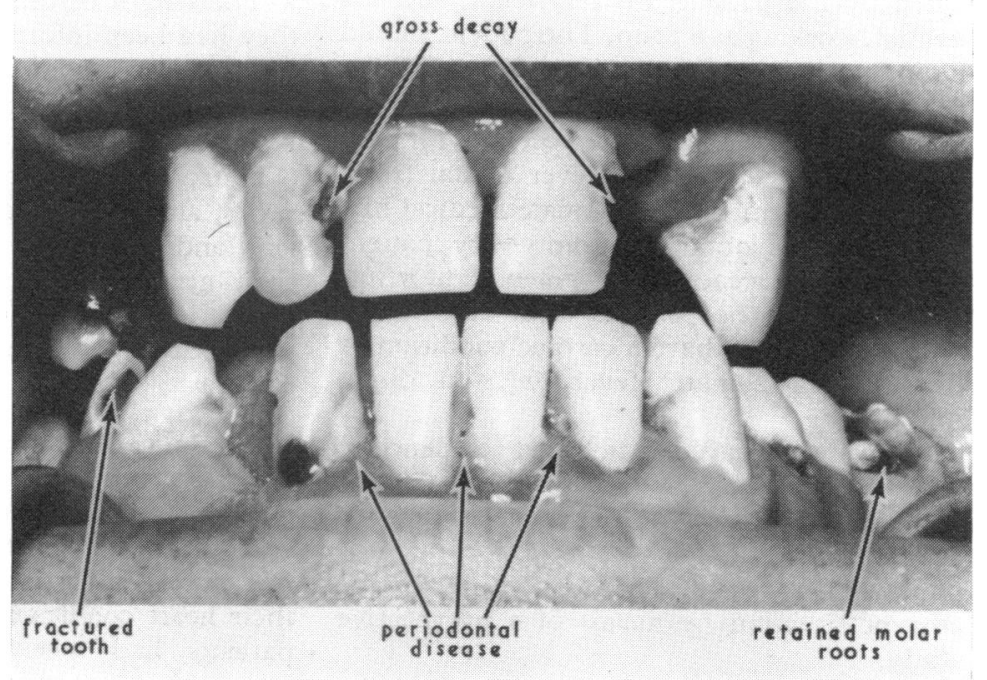




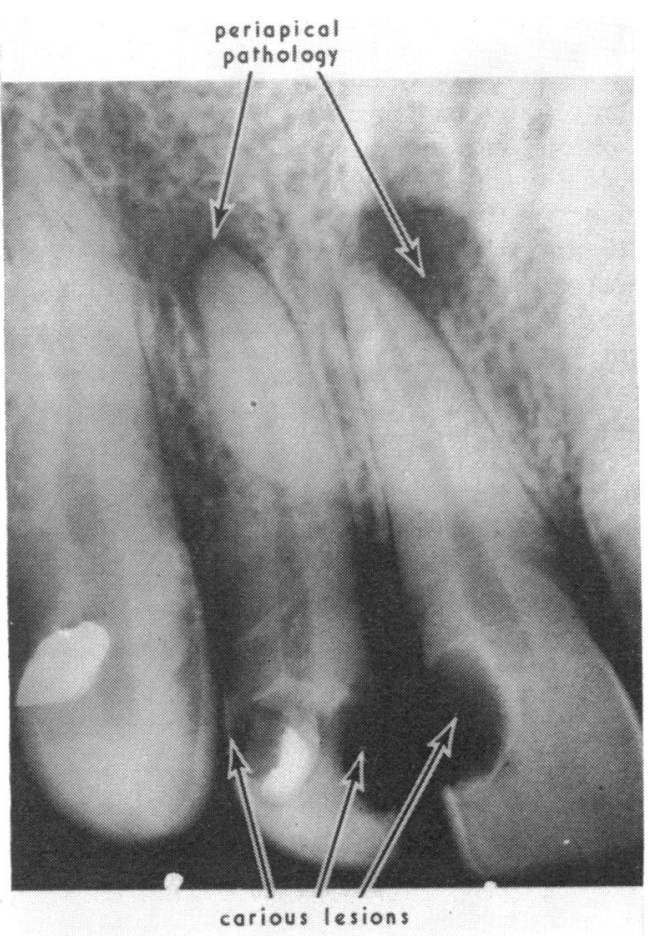

FIG. 2 Periapical radiograph of upper incisor teeth of same patient.

FIG. 3 Periapical radiograph of lower front teeth of patient who had been aware that she had rheumatic heart disease for 50 years.

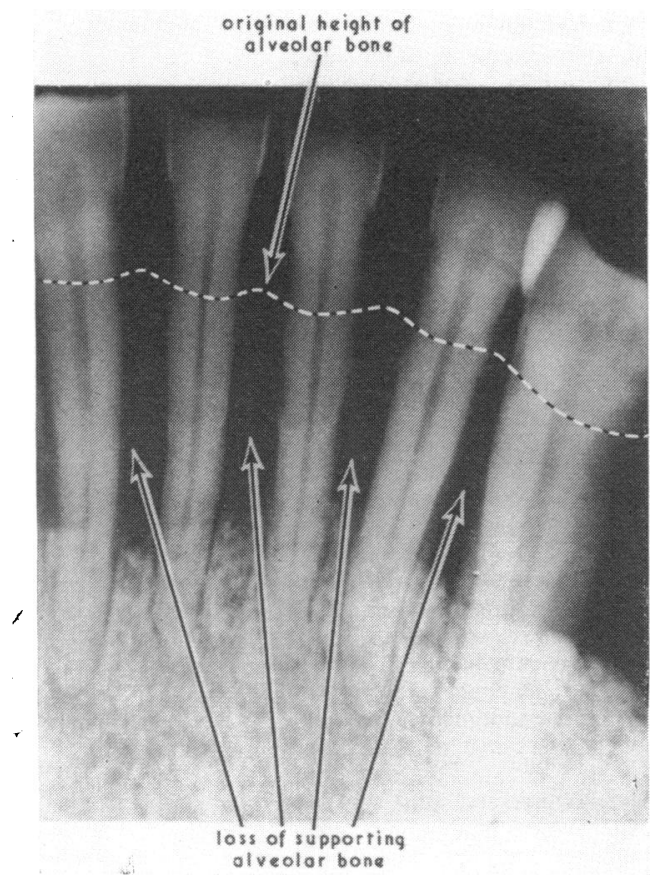

Eight weeks later she was admitted with subacute bacterial endocarditis and at necropsy vegetations were found on both mitral and aortic valves.

Another patient was admitted with pyrexia of unknown origin and a systolic murmur. A clinical diagnosis of subacute bacterial endocarditis was made though repeated blood cultures were negative. Six weeks previously two teeth had been extracted without inquiries concerning relevant medical history having been made, or antibiotic cover being instituted.

\section{Discussion}

Past medical history More than half the patients included in this survey had valvar damage which was probably the result of rheumatic fever in childhood or adolescence. The vast majority of patients and their medical advisers had been aware of their heart lesion for many years. This, together with the fact that 72 per cent of them attended regularly for medical examination, suggests that they were convinced of the need for regular monitoring of their cardiac status.

Past dental history Conversely 70 per cent (Group B) sought dental care only for the relief of pain. Patients who seek treatment on such an 'emergency' basis usually only wish to have a painful tooth extracted and often do not divulge their medical history readily, as they fear it may delay the relief of their dental symptoms.

Radiographic evidence of periapical pathology associated with grossly decayed teeth or retained roots was prevalent in Group B. The treatment of these lesions frequently involves the use of antibiotics before surgical intervention, which may have to be performed under general anaesthesia. Such conditions are often a result of neglect, and this finding is unfortunate in a group of patients in whom every possible preventive measure should be undertaken.

Edentulous patients The finding of oral candidiasis and a denture granuloma emphasizes the need for regular oral examination and denture servicing in the edentulous patient, especially in view of findings in this study and the occurrence of subacute bacterial endocarditis associated with denture ulcers in previously reported cases (Davies, x957; Dormer, I958; Massaro and Katz, I960; Cameron, 1971; Croxson et al., 1971; Simon and Goodwin, I97I). 


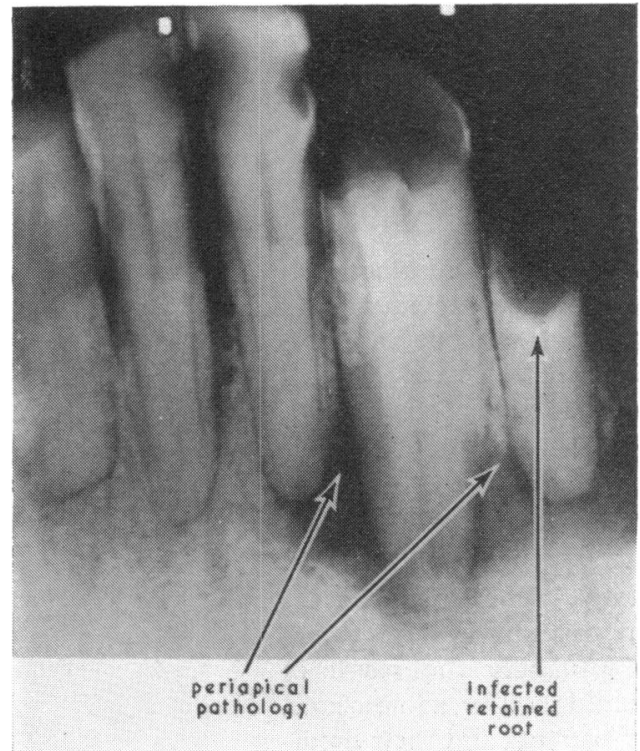

FIG. 4 Radiograph of infected roots; this patient had mitral stenosis and aortic incompetence and was unaware of importance of oral health.

Preventive measures Though I2 patients (24\%) knew that special measures should be taken before dental treatment, very few of them were aware of either the importance of, or the reason for, these safeguards. Many confused the need for antibiotic cover with 'local', 'gas', or 'injections'.

This finding is similar to those reported by other workers. McGowan and Tuohy (1968) found that only 19 per cent of their II 3 patients 'at risk' had been warned that any dental surgical treatment would require special precautions by way of antibiotic cover. While Harvey and Capone (I96I) stated that $21 \cdot 7$ per cent from their group of 258 patients with heart disease understood that antibiotic prophylaxis was necessary before extractions.

The finding that 86 per cent of the patients had never been questioned concerning their cardiac condition by a dental practitioner is very disappointing, for history-taking with special reference to rheumatic fever and associated medical conditions has long been standard teaching in dental schools. A similar finding ( $84 \%$ ) was reported by McGowan and Tuohy (1968) in their larger survey.

The immediate past dental history of the two patients admitted with subacute bacterial endocarditis is of interest for it confirms that dental procedures are still being undertaken on patients at risk without adequate precautions being instituted.

\section{Recommendations}

The results of this small survey reveal an undesirable and disturbing state of affairs. Virtually all of the oral lesions and dental sepsis found could have been prevented if the patients had been persuaded of the vital importance of preventive dentistry, regular dental care, the maintenance of dental health, and the need for antibiotic cover where indicated.

It appears prudent, at the time a heart lesion is diagnosed, to institute a full dental examination, including radiography, and further examination at frequent and regular intervals, as this ensures early diagnosis and treatment of dental lesions. Consideration should be given to the advisability of patients being issued with a warning card on which the cardiac condition, drug therapy, and suggested prophylactic measures to be taken before dental manipulations would be recorded, together with the name, address, and telephone number of the attending physician.

A medical history should be obtained from every patient before the institution of dental treatment, and this practice should be an invariable routine.

Clearly much remains to be done to improve the co-operation between the physician and the dental surgeon so that the dental needs of every susceptible patient can be catered for more adequately.

\section{References}

American Heart Association (1965). Prevention of bacterial endocarditis. Circulation, 31, 953.

Beeley, L. (1969). Teeth, streptococcus viridans and subacute bacterial endocarditis. British Dental fournal, 127, 424.

Braimbridge, M. V. (1969). Cardiac surgery and bacterial endocarditis. Lancet, $1,1307$.

British Medical fournal (1967). Leading article. Changing face of infective endocarditis. 2, 389.

British Medical fournal (197I). Leading article. Penicillin and the mouth flora. 2, 63 .

Cameron, I. W. (197I). Subacute bacterial endocarditis in an edentulous patient. British Dental fournal, I30, 404.

Cohn, L. H., Roberts, W. C., Rockoff, S. D., and Morrow, A. G. (1966). Bacterial endocarditis following aortic valve replacement. Circulation, 33, 209.

Croxson, M. S., Altmann, M. M., and O'Brien, K. P. (I97I). Dental status and recurrence of streptococcus viridans endocarditis. Lancet, I, 1205.

Cutcher, J. L., Goldberg, J. R., Lilly, G. E., and Jones, J. C. (I97I). Control of bacteremia associated with extraction of teeth. Part II. Oral Surgery, Oral Medicine and Oral Pathology, 31, 602.

Davies, J. V. S. A. (1957). Subacute bacterial endocarditis. British Medical fournal, $\mathrm{I}, 82 \mathrm{I}$.

Dormer, A. E. (1958). Bacterial endocarditis. Survey of patients treated between 1945 and 1956 . British Medical fournal, 1, 63.

Elliott, S. D. (1939). Bacteriaemia and oral sepsis. Proceedings of the Royal Society of Medicine, 32, 747. 
Fleming, H. A. (1970). Bacterial endocarditis. Practitioner, 204, 238.

Harvey, W. P., and Capone, M. A. (196I). Bacterial endocarditis related to cleaning and filling of teeth. American fournal of Cardiology, 7, 793.

Helsham, R. W. (1960). Some observations on the subject of roots of teeth retained in the jaws as a result of incomplete exodontia. Australian Dental fournal, 5, 70 .

Hobson, F. G., and Juel-Jensen, B. E. (1956). Teeth, streptococcus viridans, and subacute bacterial endocarditis. British Medical fournal, 2, I50I.

Hovell, J. H. (1970). Teeth, streptococcus viridans and subacute bacterial endocarditis. British Dental fournal, 128, 429.

Jolly, M., and Drucker, D. B. (1971). Prevention of bacterial endocarditis. British Dental fournal, 131, 539.

Jones, J. C., Cutcher, J. L., Goldberg, J. R., and Lilly, G. E. (1970). Control of bacteremia associated with extraction of teeth. Part I. Oral Surgery, Oral Medicine and Oral Pathology, 30, 454.

Lancet (197I). Editorial. Prevention of infective endocarditis. 2, 589.

McGowan, D. A., and Tuohy, O. (1968). Dental treatment of patients with valvular heart disease. British Dental fournal, 124, 519.

Massaro, D., and Katz, S. (I960). Subacute bacterial endocarditis due to streptococcus viridans in an edentulous man. New England fournal of Medicine, 263, 91 I.

Northrop, P. M., and Crowley, M. C. (1943). The prophylactic use of sulfathiazole in transient bacteremia following the extraction of teeth. Fournal of Oral Surgery, 1, 19.

Okell, C. C., and Elliott, S. D. (1935). Bacteriaemia and oral sepsis with special reference to the aetiology of subacute endocarditis. Lancet, 2, 869.
Phillips, I., and Warren, C. (1972). Antibiotic sensitivity of oral streptococci following penicillin, and of streptococci causing endocarditis. In Proceedings of the 7th International Congress of Chemotherapy, Prague, 1971.

Robinson, L., Kraus, F. W., Lazensky, J. P., Wheeler, R. E., Gordon, S., and Johnson, V. (I950a). Bacteremias of dental origin. I. A review of the literature. Oral Surgery, Oral Medicine and Oral Pathology, 3, 519.

Robinson, L., Kraus, F. W., Lazensky, J. P., Wheeler, R. E., Gordon, S., and Johnson, V. (1950b). Bacteremias of dental origin. II. A study of the factors influencing occurrence and detection. Oral Surgery, Oral Medicine and Oral Pathology, 3, 923.

Rogosa, M., Hampp, E. G., Nevin, T. A., Wagner, H. N., Driscoll, E. J., and Baer, P. N. (I960). Blood sampling and cultural studies in the detection of postoperative bacteremias. Fournal of the American Dental Association, 60, 17 I.

Scopp, I. W., and Orvieto, L. D. (1971). Gingival degerming by povidone-iodine irrigation: bacteremia reduction in extraction procedures. Fournal of the American Dental Association, 83, 1294.

Simon, D. S., and Goodwin, J. F. (1971). Should good teeth be extracted to prevent streptococcus viridans endocarditis ? Lancet, I, 1207.

Tozer, R. A., Boutflower, S., and Gillespie, W. A. (1966). Antibiotics for prevention of bacterial endocarditis during dental treatment. Lancet, I, 686.

Requests for reprints to Allan R. Thom, Esq., Department of Orthodontics, Royal Dental Hospital of London, Leicester Square, London W.C.2. 